\title{
Malignant Neoplasm Burden in Nepal - Data from the Seven Major Cancer Service Hospitals for 2012
}

\author{
Chin Bahadur Pun ${ }^{1 *}$, Kishore K Pradhananga ${ }^{2}$, Bhola Siwakoti ${ }^{3}$, Krishna \\ Subedi $^{4}$, Malcolm A Moore ${ }^{3}$
}

\begin{abstract}
In Nepal, while no population based cancer registry program exists to assess the incidence, prevalence, morbidity and mortality of cancer, at the national level a number of hospital based cancer registries are cooperating to provide relevant data. Seven major cancer diagnosis and treatment hospitals are involved, including the BP Koirala Memorial Cancer hospital, supported by WHO-Nepal since 2003. The present retrospective analysis of cancer patients of all age groups was conducted to assess the frequencies of different types of cancer presenting from January 1st to December 31st 2012. A total of 7,212 cancer cases were registered, the mean age of the patients being 51.9 years. The most prevalent age group in males was 60-64 yrs $(13.6 \%)$, while in females it was 50-54 yrs (12.8\%). The commonest forms of cancer in males were bronchus and lung (17.6\%) followed by stomach (7.3\%), larynx (5.2\%) and non Hodgkins lymphoma (4.5\%). In females, cervix uteri (19.1\%) and breast $(16.3 \%)$, were the top ranking cancer sites followed by bronchus and lung $(10.2 \%)$, ovary $(6.1 \%)$ and stomach $(3.8 \%)$. The present data provide an update of the cancer burden in Nepal and highlight the relatively young age of breast and cervical cancer patients.
\end{abstract}

Keywords: Cancer registration data - Nepal - burden of malignancies - age distribution

Asian Pac J Cancer Prev, 16 (18), 8659-8663

\section{Introduction}

Non-communicable disease, particularly cancer and cardiovascular disease are emerging public health problems in developing countries. The magnitude of the problem of cancer, in terms of its large number, warrants particular attention of policymakers and planners to evolve national programs of the action to develop, implement, coordinate and also to evaluate the cancer control activities in individual countries (Gupta et al.,1993). According to GLOBOCAN 2012, an estimated 14.1 million new cancer cases and 8.2 million cancer related deaths occurred, compared with 12.7 million and 7.6 million, respectively, in 2008 (Ferlay et al., 2012).

The importance of cancer registry data for development of national cancer control programs has already been stressed in the context of South Asia (Bhurgri, 2004). In Nepal, a hospital based cancer registry (HBCR) program was started from 1997 in 3 cancer diagnosing and treating hospitals in Kathmandu. Since 2003, with the support of WHO-Nepal the HBCR program expanded to cover 7 major cancer treated service available hospitals in coordination with BP Koirala Memorial Cancer
Hospital. While there is no population based cancer registry program, an initial assessment of incidence was published by Pradhananga et al. in 2009. It is known that approximately 8,000-10,000 cancer deaths annually in Nepal, the most common cancer site in males being the lung, followed by the oral cavity and stomach, while the first three in females were found to be cervix uteri, breast and lung (Mishra et al., 2015). In another survey, ovarian $(14 \%)$, stomach $(14 \%)$ and lung $(10 \%)$ were the main cancer sites, accounting for $38 \%$ of the total (Bhandari et al., 2014)

The land area of the country is $147,181 \mathrm{sq} \mathrm{kms}$ and is bordered by China in the north, and India on all other side. According to census 2011, the population was projected as 29,128,517 in 2012, with 14,621,285 males and $14,507,232$ females. About $34.2 \%$ of the total population is below 14 years age group and only $15 \%$ are above $60 \mathrm{yrs}$ of age. The life expectancy of males is 64.9 and in females is 67.4.The average literacy rate is $65.9 \%$ (Central Bureau of Statistics, Nepal). The size of the country, relatively inaccessibility of distant regions and these demographic factors all contribute to difficulties in providing accurate cancer statistics. However, by pooling the cases presenting in the main urban centers, a picture of the essential nature

${ }^{1}$ Executive Director, ${ }^{2}$ Cancer Prevention, Control and Research Department, BP Koirala Memorial Cancer Hospital, Bharatpur, Nepal, ${ }^{3}$ ASEAN Cancer Epidemiology Research Group, Faculty of Public Health, Khon Kaen University, Khon Kaen, Thailand *For correspondence: chinbahadurpun@hotmail.com 
Table 1. Sex-wise Distribution of Cancer Cases from Different Hospitals, 2012

\begin{tabular}{|c|c|c|c|c|c|c|c|}
\hline \multirow[t]{2}{*}{ SN Hospital Name } & \multirow[t]{2}{*}{ Location } & \multicolumn{2}{|c|}{ Males } & \multicolumn{2}{|c|}{ Females } & \multicolumn{2}{|c|}{ Total } \\
\hline & & Number & $\%$ & Number & $\%$ & Number & $\%$ \\
\hline 1. BPK Memorial Cancer Hospital & Bharatpur & 1,511 & 45.9 & 1796 & 45.8 & 3,307 & 45.9 \\
\hline 2. Bhaktapur Cancer Hospital & Bhaktapur & 665 & 20.2 & 848 & 21.6 & 1,513 & 21.0 \\
\hline 3. Bir Hospital & Kathamndu & 495 & 15.0 & 455 & 11.6 & 950 & 13.2 \\
\hline 4. TU Teaching Hospital & Kathmandu & 276 & 8.4 & 349 & 8.9 & 625 & 8.7 \\
\hline 5. Kanti Children Hospital & Kathmandu & 38 & 1.2 & 31 & 0.8 & 69 & 1.0 \\
\hline 6. BPK Institute of Health Science & Dharan & 239 & 7.3 & 306 & 7.8 & 545 & 7.6 \\
\hline 7. Manipal Teaching Hospital & Pokhara & 67 & 2.0 & 136 & 3.5 & 203 & 2.8 \\
\hline Total & & 3,291 & 100 & 3,921 & 100 & 7,212 & 100 \\
\hline
\end{tabular}

of the problem can be generated on which to base future cancer control activities.

\section{Materials and Methods}

In this study the seven major cancer service providing hospitals were BP Koirala Memorial Cancer Hospital as the national cancer hospital in Bharatpur, Bhaktapur cancer hospital, Bir, TU Teaching and Kanti Children Hospitals in Kathmandu and in the east of the country the BPK Institute of Health Science in Dharan and in the west the Manipal Teaching hospital, Pokhara.

All cases diagnosed by a histopathologist, hematologist and/or radiologist and treated for cancer with name, age, sex, occupation, religion, district and diagnosis from January 1st to 31st December 2012 were abstracted from medical record sections in the National cancer registry

Table 2. Collated Data for Most Prevalent Cancers in the Seven Hospitals

\begin{tabular}{lrrrr}
\hline SN Cancer site & ICD-10 No. cancers & $\%$ & CIR \\
\hline Males & & & & \\
1. Bronchus \& Lung & C-34 & 579 & 17.6 & 4.0 \\
2. Stomach & C-16 & 240 & 7.3 & 1.6 \\
3. Larynx & C-32 & 170 & 5.2 & 1.2 \\
4. Non Hodgkin's & C-85 & 148 & 4.5 & 1.0 \\
5. Urinary Bladder & C-67 & 127 & 3.9 & 0.9 \\
6. Unspecified Mouth & C-06 & 123 & 3.7 & 0.8 \\
7. Brain & C-71 & 104 & 3.2 & 0.7 \\
8. Rectum & C-20 & 101 & 3.1 & 0.7 \\
9. Other ill-defined & C-76 & 100 & 3.0 & 0.7 \\
10.Connective tissue & C-49 & 85 & 2.6 & 0.6 \\
11. Other cancers & - & 1514 & 46.0 & 10.4 \\
$\quad$ All cancers & - & 3291 & 100.0 & 22.5 \\
Females & & & & \\
1. Cervix Uteri & C-53 & 747 & 19.1 & 5.1 \\
2. Breast & C-50 & 641 & 16.3 & 4.4 \\
3. Bronchus \& Lung & C-34 & 398 & 10.2 & 2.7 \\
4. Ovary & C-56 & 238 & 6.1 & 1.6 \\
5. Stomach & C-16 & 148 & 3.8 & 1.0 \\
6. Gall bladder & C-23 & 144 & 3.7 & 1.0 \\
7. Thyroid & C-73 & 122 & 3.1 & 0.8 \\
8. Other ill-defined sites C-76 & 88 & 2.2 & 0.6 \\
9. Brain & C-71 & 78 & 2.0 & 0.5 \\
10.Rectum & C-20 & 76 & 1.9 & 0.5 \\
11. Other cancers & - & 1241 & 31.7 & 8.5 \\
$\quad$ All cancers & - & 3921 & 100.0 & 26.8 \\
\hline
\end{tabular}

ICD-10 (International Classification of Diseases,10th revision); CIR, Crude incidence rate forms from all hospitals. All forms were collected for analysis and all double/multiple entry cancer cases were excluded by cross checking name, age, sex, address and hospital registered number of each patient and all cases coded as per ICD-O, 3rd edition(Fritz and Percy, 2000). Information on other variables was coded according to the international guidance (Jenson et al, 2003). These codes were converted to ICD-10(1994) for tabulation. Data were entered and analyzed using SPSS 10.1 (SPSS Inc. Chicago, USA) and relative frequency were obtained.

\section{Results}

During the study period 7,212 cancer cases were recorded as summarized in Table 1. Overall, female cancer cases $(54.4 \%)$ were more common than in males $(45.6 \%)$ (ratio of 1:1.19). Most cancer cases were registered in BP Koirala Memorial Cancer Hospital followed by Bhaktapur Cancer Hospital and Bir Hospital. The number of cases by site (ICD-10) and percentages of various cancer cases for males and females are given in Table.

In addition, data for the age distribution of the most
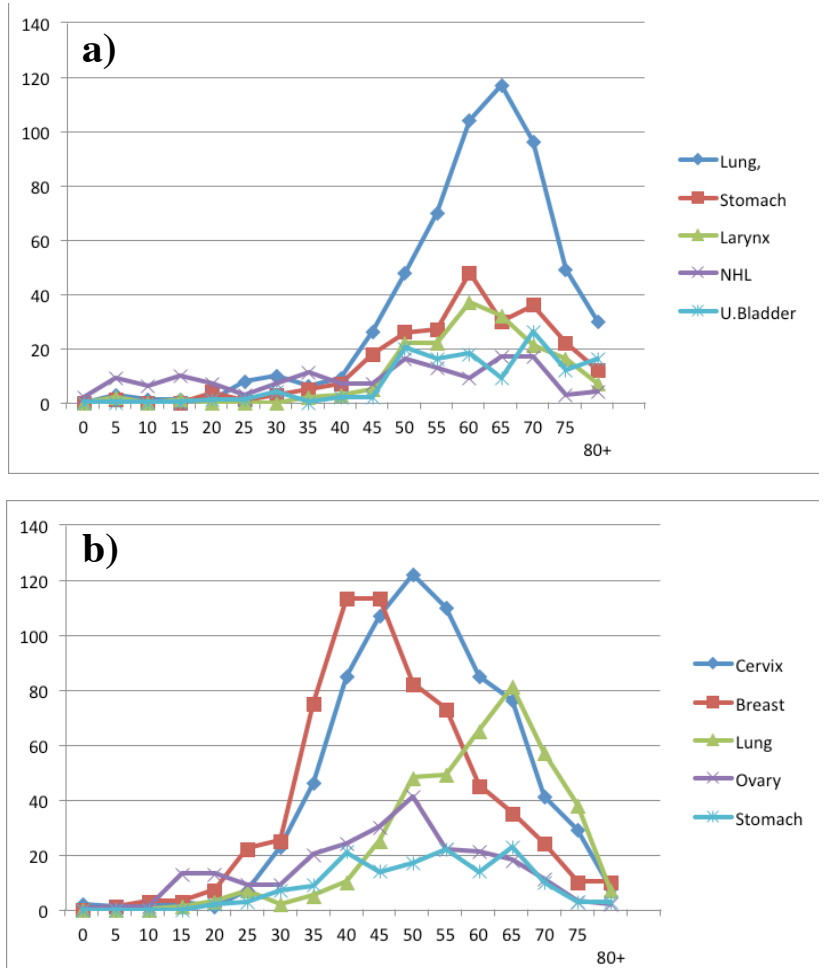

Figure 1. Age Distribution of Cancer Cases in a) Males and b) Females 
common cancers are given in Figure 1 for males and females, separately. In the youngest age group of 0-15 years, lymphomas and lekemias as well as connective tisue tumours were the most prevalent, as well as nervous tissue lesions. A relatively young age for breast and cervical cancers in females was particularly evident.

\section{Discussion}

The results of this retrospective study of cancer data collected for analysis from seven cancer diagnosis and treatment major hospitals from 1st January to 31st December 2012 in Nepal were clearly in line with earlier reports (Pradhananga et al., 2009; Bhandari et al., 2014 Mishra et al., 2015). In the Himalayan Institute of Medical Sciences, Dehradun, India with low socio-economic status like in Nepal, the top five cancers in males were lung, larynx, lymphoma, oesophagus and stomach, while in females they were breast, cervix, gallbladder, ovary and oesophagus (Gaur et.al., 2006) Compared to the earlier report from the same hospitals (Pradhananga et al., 2009), in males the percentage rates for trachea/lung and larynx were increased (from 14.6 to 17.6, and 3.7 to 5.2) while those for the buccal cavity appeared decreased ( 7.8 to 3.7 ). The latter is in agreement with the general trends within South Asia for reduction over time (Moore et al., 2010). In females, the main change was increase in breast and decrease in cervical cancer rates, again reminiscent of data for India (Moore et al., 2010). Clearly there can a great deal of geographical variation, for example as reported for different regions of India (Nandakumar et al., 2005) and possibility that this might also be the case in Nepal deserves particular exploration. Thus more comprehensive hospital-based registries for regions (eg Binu et al., 2007) might reward investment if geographical origin of patients can be monitored.

Regarding the number one cancer overall, in the lung, this is also the case for many Indian registries and Karachi (Curado et al., 2007; Forman et al., 2012). Unfortunately, we do not have data on the relative incidences of squamous cell carcoma and adenocarcinoma, the former generally predominating in males, presumably because of smoking habits, and the latter in females (Curado et al., 2007; Moore et al., 2010; Forman et al., 2012). A survey among rural communities of Nepal by Pandey et al (1988) showed that in the $20+$ yrs age group $85.4 \%$ of men and $62.4 \%$ of women were tobacco users. The prevalence of smokeless tobacco use, as well as smoking, is high, particularly among males and disadvantaged groups (Sinha et al., 2012). More recently, it was documented that older women are also very likely to smoke, especially those with a lower socioeconomic status (Pandey and Lin, 2013). An inverse association was observed between education and lung cancer risk also observed greater lung cancer risk among unmarried individuals, and lower risk in individuals who lived in the Central region compared to the West (Hashibe et al., 2011). Awareness of lung cancer by tobacco use and other risk factors varied with socioeconomic status amongst residents of Pokhara, Despite their awareness of smoking as a risk factor for lung cancer, most of them still continue to smoke (Chawla et al., 2010). Furthermore, even medical student perceptions about the cause of lung cancer may be influenced by their smoking behavior and there was little knowledge of public health measures for smoking control (Khatiwada et al., 2012). Late presentation leading to advanced disease and poor pulmonary reserves preclude lung cancer resection in most cases (Thapa and Sayami, 2014), so another focus must be on eductaion as to symtpoms for early detection.

The second most common cancer in males was of the larynx, in line with earlier data for Nepal (Lasrado et al., 2012), which was also leading cancer sites in India and Pakistan (Curado et al., 2007; Moore et al., 2010; Forman et al., 2012). In Nepal, the supraglottic larynx is reported to be the commonest subsite to harbor laryngeal malignancy, with smoking and alcohol as prevalent risk factors (Koirala, 2015).

In this study, stomach cancer was also a leading cancer in both males and females. In India there is considerable variation among registries in this cancer (Nandakumar et al., 2005; Moore et al., 2010). Gastric cancer in Nepal is usually diagnosed at an advanced stage and has a poor prognosis, so that early detection is the key to improve the survival (Sah et al., 2015). The relatively low incidence of gastric cancer in Nepal can be attributed to low gastric mucosal atrophy, but mountainous subjects have highrisk gastric mucosal status, which could be considered a high-risk population in Nepal (Miftahussurur et al., 2015).

While cancers of the liver, colorectum (CRC) and prostate appeared rare in the present study, it has been reported CRC among Nepalese young adults accounts for a high proportion. Although right sided colonic cancer has been increasing, rectum is the commonest site (Kansakar and Singh, 2012). Given the association with diabetes mellitus, know to be an increasingly important problem in Nepal (Bhandari et al., 2014), future work should focus more attention on this type of neoplasm. Elevated fasting levels of serum insulin also appear to be associated with a higher risk of prostate cancer in Nepal (Pandeya et al., 2014). While main etiological factors for $\mathrm{HCC}$ are $\mathrm{HBV}$, $\mathrm{HCV}$, alcohol and cryptogenic cirrhosis, also the role of elevated insulin level in increasing $\mathrm{HCC}$ risk appeared consistent, influencing incidence, risk of recurrence, overall survival, and treatment-related complications in HCC patients in Nepal (Jha et al., 2012; Gupta et al., 2013).

Among females cancer of the cervix uteri is common cancers in the developing countries but in developed countries breast cancer is the leading cancer (Curado et al., 2007; Moore et al., 2010; Forman et al., 2012). There is an urgent need for a reinvigorated and tailored approach to cervix cancer prevention among the educated youth in India, Nepal and Srilanka (Joy et al., 2011). Recent data predict a significant increase in cervical cancer cases in the future, suggesting the need for more focus and resource allocation on cervical cancer screening and treatment (Sathian et al., 2013). Self-collected sampling methods should be the subject of additional research in Nepal for screening HR-HPV, associated with pre-cancer lesions and cancer, in women in rural areas with limited access to health services (Johnson et al., 2014) In the context of limited screening services in Nepal, the efforts should be 
to reduce the diagnostic delay especially patient and health care provider delay for early detection and reduction of mortality rate of cervical cancer (Gyenwali et al., 2014) Risk factors for cervix cancer like early age at marriage, early age at first birth, multiparity, poor genital hygiene and infection with HPV virus infection are common in Nepal. Health education programs which are effective not only in increasing knowledge about cervical cancer and pap smear test but also effective in positively changing attitude towards the test should be organized to increase pap smear coverage (Ranabhat et al., 2014).

Breast cancer here proved to have now overtaken cervical cancer in terms of incidence, as in the majority of countries of Asia (Curado et al., 2007; Moore et al., 2010; Forman et al., 2012). The fact that young Nepalese women accont for over one quarter of all female breast cancers, many being diagnosed at an advanced stage (Sharma et al., 2005; Thapa et al., 2013) is of particular importance. The level of awareness of breast cancer, including knowledge of warning signs and BSE, is sub-optimal among Nepalese women (Sathian et al., 2014). low knowledge on breast cancer, risk factors and screening practice among women groups (Shrestha, 2012). Community interventions have been a focus in Bangladesh (Ansink et al., 2008) and Kolkaatta (Basu et al., 2006) and deserve emphaiss in the Nepali context. In both breast and cervical cancer cases compliance with both screening guidelines and subsequent referral and treatment are necessary (Dinshaw et al., 2007a;2007b). It should be noted that breast self examination has been validated in the Nepal setting (Tara et al., 2008).

Our present results claeraly impact on planning and resource allocation for treatment, incuding need for radiotherapy. In Nepal, the cancer cases estimated using a cubic model showed a steady increase in the total frequency of (including male and female cancer cases) following the year 2010 (Sathian et al., 2010) so that demand for different treatment types needs more attention.

In conclusion, in males the incidence of tobacco related cancers and in females, breasts cervix and other gynecological cancer are high in Nepal. Therefore ,primary prevention of lung and other tobacco related cancers by implementation of tobacco control and screening of cervix and breast cancer are necessary on a wider scale from government level. In the absence of population based cancer registry, incidence, prevalence and mortality data are not available, with death certification also not feasible (Kumar and Yeole, 2005), studies like ours provide useful information that can be utilized for health planning in future research.

\section{References}

Ansink AC, Tolhurst R, Haque R, et al (2008). Cervical cancer in Bangladesh: community perceptions of cervical cancer and cervical cancer screening. Trans $R$ Soc Trop Med Hyg, 102, 499-505.

Basu P, Sarkar S, Mukherjee S, et al (2006). Women's perceptions and social barriers determine compliance to cervical screening: results from a population based study in India. Cancer Detect Prev, 30, 369-74.

Bhandari GP, Angdembe MR, Dhimal M, Neupane S, Bhusal C

8662 Asian Pacific Journal of Cancer Prevention, Vol 16, 2015
(2014). State of non-communicable diseases in Nepal. BMC Public Health, 14, 23.

Bhurgri Y ( 2004). Karachi Cancer Registry Data--implications for the National Cancer Control Program of Pakistan. Asian Pac J Cancer Prev, 5, 77-82.

Binu VS, Chandrashekhar TS, Subba SH, et al (2007). Cancer pattern in Western Nepal: a hospital based retrospective study. Asian Pac J Cancer Prev, 8, 183-6.

Chawla R, Sathian B, Mehra A, 2010). Awareness and assessment of risk factors for lung cancer in residents of Pokhara Valley, Nepal. Asian Pac J Cancer Prev, 11, 1789-93.

Curado MP, Edwards B, Shin HR, et al (Eds) (2007). Cancer Incidence in Five Continents Vol. IX. IARC Scientific Publications No 160, IARC, Lyon.

Dinshaw K, Mishra G, Shastri S, et al (2007a). Determinants of compliance in a cluster randomised controlled trial on screening of breast and cervix cancer in Mumbai, India. 1. Compliance to screening. Oncology, 73, 145-53.

Dinshaw K, Mishra G, Shastri S, et al (2007b). Determinants of compliance in a cluster randomised controlled trial on screening of breast and cervix cancer in Mumbai, India. 2. Compliance to referral and treatment. Oncology, 73, 154-61.

Forman D, Bray F, Brewster DH, et al; editors (2014). Cancer Incidence in Five Continents, Vol. X. IARC Scientific Publication No. 164. Lyon: International Agency for Research on Cancer.

Gaur DS, Kishore S, Harsh M, Kusum A, Bansal R (2006). Pattern of cancers amongst patients attending Himalayan Institute of Medical Sciences, Dehradun. Indian J Pathol Microbiol, 49, 193-8.

Gupta SP, Mittal A, Sathian B, Jha DK (2013). Elevated serum insulin is an independent risk factor for hepatocellular carcinoma: a case control study from Nepal. Asian Pac J Cancer Prev, 14, 7331-3.

Gyenwali D, Khanal G, Paudel R, et al (2014). Estimates of delays in diagnosis of cervical cancer in Nepal. $B M C$ Womens Health, 14, 29.

Ferlay J, Soerjomataram I, Ervik M, et al (2012).GLOBOCAN 2012 v 1.0, Cancer Incidence and Mortality Worldwide: IARC CancerBase No. 11 [Internet]. Lyon, France: International Agency for Research on Cancer; 2013. Available from: http:// globocan.iarc.fr, accessed on 26.12.2015.

Ghumare SS, Cunningham JE (2007). Breast cancer trends in Indian residents and emigrants portend an emerging epidemic for India. Asian Pac J Cancer Prev, 8, 507-12.

Hashibe M, Siwakoti B, Wei M, et al (2011). Socioeconomic status and lung cancer risk in Nepal. Asian Pac J Cancer Prev, 12, 1083-8.

Jha DK, Mittal A, Gupta SP, Pandeya DR, Sathian B (2012). Association of type II diabetes mellitus with hepatocellular carcinoma occurrence--a case control study from Kathmandu Valley. Asian Pac J Cancer Prev, 13, 5097-9.

Johnson DC, Bhatta MP, Smith JS, et al (2014). Assessment of high-risk human papillomavirus infections using clinicianand self-collected cervical sampling methods in rural women from far western Nepal. PLoS One, 9, e101255.

Joy T, Sathian B, Bhattarai C, Chacko J (2011). Awareness of cervix cancer risk factors in educated youth: a crosssectional, questionnaire based survey in India, Nepal, and Sri Lanka. Asian Pac J Cancer Prev, 12, 1707-12.

Kansakar P, Singh Y (2012). Changing trends of colorectal carcinoma in Nepalese young adults. Asian Pac J Cancer Prev, 13, 3209-12.

Khatiwada P, Kayastha SR, Pant P, et al (2012). Understanding of tobacco and lung cancer among medical students in Kathmandu University School of Medical Sciences (KUSMS). Kathmandu Univ Med J, 10, 60-5. 
Koirala K (2015). Epidemiological study of laryngeal carcinoma in western Nepal. Asian Pac J Cancer Prev, 16, 6541-4.

Kumar AV, Yeole BB (2005). Assessing cancer burden in rural India: an analysis by cause of death statistics. Asian Pac $J$ Cancer Prev, 6, 221-3.

Lasrado S, Prabhu P, Kakria A, et al (2012). Clinicopathological profile of head and neck cancers in the Western development region, Nepal: a 4-year snapshot. Asian Pac J Cancer Prev, 13, 6059-62.

Miftahussurur M, Sharma RP, Shrestha PK, et al (2015). Helicobacter pylori infection and gastric mucosal atrophy in two ethnic groups in Nepal. Asian Pac J Cancer Prev, 16, 7911-6.

Mishra SR, Neupane D, Bhandari PM, Khanal V, Kallestrup P (2015). Burgeoning burden of non-communicable diseases in Nepal: a scoping review. Global Health, 11, 32.

Moore M, Ariyaratne Y, Badar F, et al (2010). Cancer epidemiology and control in southern Asia - past, present and future. Asian Pac J Cancer Prev, 11, 17-32.

Nandakumar A, Gupta PC, Gangadharan P, Visweswara RN, Parkin DM (2005). Geographic pathology revisited: development of an atlas of cancer in India. Int J Cancer, 116, $740-54$

Pandey MR, Neupane RP, Gautam A (1988). Epidemiological study of tobacco smoking behaviour among adults in a rural community of the hill region of Nepal with special reference to attitude and beliefs. Int J Epidemiol, 17, 535-41.

Pandey S, Lin Y. (2013). Tobacco use among married women in Nepal: the role of women's empowerment. Matern Child Health $J, \mathbf{1 7}, 530-8$.

Pandeya DR, Mittal A, Sathian B, Bhatta B (2014). Role of hyperinsulinemia in increased risk of prostate cancer: a case control study from Kathmandu Valley. Asian Pac J Cancer Prev, 15, 1031-3.

Pradhananga KK, Baral M, Shrestha BM (2009). Multiinstitution hospital-based cancer incidence data for Nepal: an initial report. Asian Pac J Cancer Prev, 10, 259-62.

Ranabhat S, Tiwari M, Dhungana G, Shrestha R (2014). Association of knowledge, attitude and demographic variables with cervical Pap smear practice in Nepal. Asian Pac J Cancer Prev, 15, 8905-10.

Sah JK, Singh YP, Ghimire B (2015). Presentation and outcomes of gastric cancer at a University Teaching Hospital in Nepal Asian Pac J Cancer Prev, 16, 5385-8.

Sathian B, Bhatt CR, Jayadevan S, et al (2010). Prediction of cancer cases for a hospital in Nepal: a statistical modelling. Asian Pac J Cancer Prev, 11, 441-5.

Sathian B, Fazil A, Sreedharan J, et al (2013). Statistical modelling and forecasting of cervix cancer cases in radiation oncology treatment: a hospital based study from Western Nepal. Asian Pac J Cancer Prev, 14, 2097-100.

Sathian B, Nagaraja SB, Banerjee I, et al (2014). Awareness of breast cancer warning signs and screening methods among female residents of Pokhara valley, Nepal. Asian Pac J Cancer Prev, 15, 4723-6.

Sharma A, Bandari R, Gilbert D, Sharma AK (2005). Benign and malignant breast disease presenting to Bhaktapur Cancer Hospital. Kathmandu Univ Med J, 3, 384-7.

Sinha DN, Bajracharya B, Khadka BB, e al (2012). Smokeless tobacco use in Nepal. Indian J Cancer, 49, 352-6.

Shrestha K (2012). Breast cancer knowledge and screening practice among women visited to KIST medical college. Nepal Med Coll J, 14, 308-11.

Tara S, Agrawal CS, Agrawal A (2008). Validating breast self examination as screening modalities for breast cancer in eastern region of Nepal: a population based study. Kathmandu Univ Med J, 6, 89-93.
Thapa B, Sayami P (2014). Low lung cancer resection rates in a tertiary level thoracic center in Nepal--where lies our problem? Asian Pac J Cancer Prev, 15, 175-8.

Thapa B, Singh Y, Sayami P, Shrestha UK, Sapkota R, Sayami $\mathrm{G}$ (2013). Breast cancer in young women from a low risk population in Nepal. Asian Pac J Cancer Prev, 14, 5095-9. 